\title{
Death as a Condition of Life: On the Question of Individual Immortality of Man
}

\author{
Vladimir Alexandrovich Rybin \\ Department of Philosophy, Chelyabinsk State University, Chelyabinsk, Russia
}

Email address:

wlad@csu.ru

\section{To cite this article:}

Vladimir Alexandrovich Rybin. Death as a Condition of Life: On the Question of Individual Immortality of Man. Advances in Sciences and Humanities. Vol. 7, No. 3, 2021, pp. 74-78. doi: 10.11648/j.ash.20210703.15

Received: May 15, 2021; Accepted: June 4, 2021; Published: September 8, 2021

\begin{abstract}
Nowadays, a paradoxical situation arises: scientific and technological progress is an undoubted good, but at the same time it creates a threat to the continued existence of wildlife and the human race. To overcome this contradiction, it is necessary to develop a fundamentally new and more concrete understanding of the phenomenon of life. All existing approaches to the study of life are one-sided, since they do not pay due attention to the phenomenon of death. Science connects death with an increase in entropy. Philosophy focuses on ascending evolution and puts the problem of death on the back burner. As a result, death is seen as something completely opposite to life. Such an approach naturally creates a passive attitude to death in all spheres of culture, including medicine. To overcome this situation, it is necessary to realize the fact that the existence of living organisms involves a combination of opposite processes. This is synthesis and decay, renewal and degradation, complication and simplification. Life and death form an indissoluble unity. This leads to a number of general conclusions. Death is a condition of life. The main property of living beings is the ability to die. A person is a unique being who is able to die in a special way, namely, for an extremely long time, in the process of aging. In modern medicine, this circumstance is not taken into account. Therefore, all technologies for extending a person's life are applied only to the late, final stages of the life process. A new medical doctrine is needed. Medicine should delay death at earlier stages of the life of a human individual. This means that modern diseases of civilization (cardiovascular diseases and oncology) should not be treated, but prevented by shifting them to a later date. Such an approach opens up the prospect of unlimited prolongation of the life of both an individual and the whole of humanity already beyond the limits of natural nature, that is, at the super-natural level of human culture.
\end{abstract}

Keywords: Evolution, Nature, Culture, Life, Death, Human Race, Aging, Person

\section{Introduction}

Today, there is no doubt that the modern man-made civilization, which was formed in Europe as a result of the development of science and technology, is experiencing a state of deep distress. Numerous crises, especially ecological and anthropological ones, have called into question the continued existence of the human race in its natural, evolutionarily developed form (p. 55-57) [1]. On the one hand, numerous environmental disasters on a regional and global scale are an indicator of this threat. On the other hand, the epidemic of cardiovascular and oncological diseases, as well as the emergence of new viral infections, indicate a sharp decrease in the biological resistance of the human population. The prospect of complete absorption of natural wildlife from the artificial technical sphere looks quite real (p. 23) [2]. We can also see the immediate result of this process in the form of robotization of a living person both from the side of his physical qualities (the transhumanism project) and from the side of his mental characteristics (the total digitalization of society and the dominance of artificial intelligence) (p. 343) [3].

To get out of this situation, it is necessary to understand it from the highest possible point of view, within the framework of the universal evolutionary process. According to this approach, both the living nature and the human race, together with the evolution of its ideas, are links in a certain "great chain of being" (Arthur O. Lovejoy). However, in order not to remain at the level of stating general provisions, it is necessary to answer the question about the specifics of 
each of the links in this single chain. Limiting the answer to this question to the scope of the problem indicated in the title of our work, we will characterize the studied specificity as a feature of the course of the life process, respectively, at the level of natural nature and at the level of human culture.

\section{Methodological Aspect}

Since the definition of the specificity of a certain phenomenon is carried out by distinguishing it from other phenomena in a number of properties common to all of them, another question immediately arises - the question of the basic concept that is extremely common to all of these phenomena. Since the concept of life process itself needs to be defined, then to single out life as such a basic concept means to carry out a logically unacceptable procedure. We must find some other way. It seems to us that the most productive approach looks from the position of the ratio of the special and the individual, namely, the ratio along the line of species-individual. Let us consider this circumstance in more detail.

Biological evolution, as we know, is carried out through the struggle for existence between living species. In general, the evolutionary process at the level of wildlife is carried out as the formation of new species that are morphologically different from the previous, earlier species. At the same time, not all species survive, as well as its constituent individuals. Thus, evolution in living nature is carried out according to the formula mortal species-mortal individual.

The appearance of man qualitatively transforms the process of evolution in living nature. Man uses artificial tools of labor and thus gets out of the dominant struggle for existence between species in living nature. Thus, the "great chain of being" is broken for the first time, which means a radical change in planetary evolution (p. 293-294) [4] and entails a number of consequences. First, the direction of the evolutionary process shifts from the morphological transformation of the living species themselves to the transformation of the external environment. The human species itself remains morphologically unchanged (p. 525) [5]. Second, the human species becomes dominant among other living species and acquires the ability to "exist as long as the appropriate conditions for existence on our planet are created" (p. 44) [6]. This allows us to talk about the immortality of humanity as a special species that is transformed into a genus. Third: such a position of humanity in nature transforms the life process already in the parameters of the individual, that is, within the framework of the individual human organism. This aspect requires particularly close consideration.

\section{The Human Individual and the Human Race}

First of all, there is a significant lengthening of the life span of the human individual in comparison with other living species. As an individual, a person lives to 90-100-115 years, which is more than twice the life expectancy of higher apes (p. 163) [7]. The lengthening of life expectancy in humans occurs due to the formation of a special life period - the period of aging, which is absent in lower-organized species or is extremely short (p. 55-58) [8]. Aging is a slow death. Thus, the process of dying of a human individual is stretched, and the moment of death itself is shifted to a more distant period.

As a result, at the cultural level, there is a situation in which the immortality of the human race is combined with the mortality of an individual. Thus, the ratio of species to individuals in the human world obeys the formula immortal species-mortal individual. It follows that only the human race as a whole is endowed with a full-fledged quality of life, while the life of individual people serves as a building material for the progress of culture. Death, overcome within the family, in this case is still perceived as a fatal, uncontrollable force, the superiority of which is recognized by ordinary consciousness, science, and philosophy. In this spirit, philosophers in the Soviet Union declared with pathos: an individual person is mortal, but the eternally living humanity is immortal (p. 412-413) [9]. Such a statement could hardly comfort a particular mortal individual.

However, today the prospect of the immortality of the human race already looks doubtful. The threats posed by the technological civilization put forward a new formula of the mortal species-the mortal individual. This marks the second break in the great chain of being. This gap is due to the fact that at the turning point of the XX-XXI centuries, humanity is experiencing a critical and perhaps the most difficult moment in its history. This point is connected with the need to form a special-balanced-form of interaction between nature and man (p. 12) [10]. More specifically, this is expressed in the imperative need to build this interaction not only within the framework of the special-individual, that is, the species and the individual, but within the broader framework of the universal-special-individual, that is, in the context of the relationship between living nature, the human race in the image of an extremely technicalized culture and the living human individual.

\section{Paradoxes of the Current Situation}

At first glance, this statement is nothing new. The crisis nature of the development of modern civilization was clearly and unambiguously identified in the last decades of the XX century in the theoretical developments of the Club of Rome and its associated theorists (Erich Jantsch, Dennis Meadows, Jay Forrester and others), in the concept of sustainable development. The paradox is that in the 50 years that have passed since the first alarm signals appeared, there have been no significant changes in the direction of modern civilization. A threat to life was recorded, but no real steps were taken to overcome this threat. What is the reason for this situation?

The difficulty of answering this question is due to the fact that the current threatening prospect is not the result of some 
sudden evolutionary turn. This perspective is a natural continuation of the long-term trends of historical development, which have always been considered as the most positive and significant. Until very recently, it was customary to cite the achievements of science and technology as the most convincing argument in favor of the positive significance of such trends. However, is it possible to say that thanks to science and technology, the essence of life is revealed, and, consequently, the threats to it are correctly understood?

\section{What Is Life}

In fact, there is still no complete answer to the question of what life is in its essence. Dictionaries and encyclopedias, textbooks and reference books provide a variety of definitions of life. According to purely scientific definitions, life is reduced to the laws of physics and chemistry. Within the framework of a purely philosophical understanding, life is described by abstract categories. In theological concepts, life is interpreted as a divine gift. From the point of view of esoteric theories, life is a supernatural substance. And sometimes it is claimed that life is impossible to define at all.

But if the concept of life is still given, it is given through the enumeration of its inherent qualities. For example, "living objects differ from non-living ones in their metabolism, irritability, ability to reproduce, grow, actively regulate their composition and functions, to various forms of movement, adaptability to the environment, etc." (p. 192) [11]. The imperfection of this approach is expressed, first, in the fact that such qualities can be inherent in inanimate objects (crystals "grow", and fire "multiplies", since, as Herbert Spencer noted in his theory of evolution, development in inanimate and living nature, as well as in human society, follows the same laws (p. 55-56) [12]. Secondly, the set of enumerated qualities can go to infinity.

It cannot be said that philosophy has passed over the problem of life. Even in the middle of the XIX century, such an authoritative direction as the philosophy of life was formed. For the most part, this direction includes the teachings of the metaphysical order, for example, the philosophy of Friedrich Nietzsche. But there are also teachings that are marked by the influence of science, for example, "Creative Evolution" by Henri Bergson. In his essay, life is characterized as "an upward flow, which is counteracted by the downward movement of matter" (p. 262) [13]. This definition sounds more specific, but nevertheless remains very abstract.

Philosophically thinking natural science has advanced a little further. A serious contribution to the understanding of the phenomenon of life was made by the Russian scientist V. I. Vernadsky. He associated the main property of life with the presence of a special property in living matter in the form of a continuous increase in the material and energy force of its impact on the external environment (p. 301-302) [14].

Within the framework of science itself, the highest achievement in understanding the phenomenon of life is still the synthetic theory of evolution, formed in the second half of the XX century (J. Huxley, C. Waddington, I. I. Schmalhausen and ot.), as well as subsequent discoveries in the field of biological theory and practice (for example, advances in plant breeding, decoding the human genome). However, the general scientific definition of life has not been developed, and the phenomenon of life itself has not become less mysterious (p. 12-13) [15]. Some factor of the life process still remains unaccounted for. This statement is proved by the fact that, based on the available scientific knowledge, the artificial reconstruction of living organisms is still an unattainable goal.

\section{A New Approach: Death as a Condition of Life}

The limitations of all previous scientific and philosophical concepts are caused by the fact that they trace only the ascending line of the existence of living organisms. This line is connected with development, with growth and improvement. Meanwhile, this is only one side of the evolutionary process. Evolution presupposes renewal, and renewal always presupposes the disintegration and death of those components of the evolutionary process that are unable to adapt to new conditions.

This fact is recognized, but in fact it is not taken into account. The descending line of existence, which is associated with the disintegration, degradation and death of living systems, is excluded from the sphere of modern scientific knowledge. It is believed that the phenomenon of death is exhaustively explained by the second law of thermodynamics and the entropy principle that follows from it. In modern natural science, the following logic applies: the world is dominated by non-equilibrium processes that occur with decreasing energy; the disintegration of everything that exists is an objective regularity; therefore, there is no point in explaining death in any particular way.

Therefore, the understanding of death on the part of representatives of science actually does not go beyond the ordinary consciousness and superficial observations. Life is interpreted in the spirit of Epicurus, that is, as something absolutely opposed to death and incompatible with it: there is life - there is no death, death comes - life goes. At first glance, everything is obvious and simple.

This deceptive simplicity is confirmed by the fact that such one-line patterns do exist, but they are realized only in inanimate nature, in the inorganic world. These are singleline processes, where either only synthesis (for example, crystal growth) or only decay (iron oxidation) occurs. There is no death in this world, it is not dead, it is just inanimate. Death appears only in the world of living, organic nature, that is, in the world of living systems (p. 70) [6]. The living systems themselves are reproduced through a combination of two lines - the lines of renewal and degradation, consumption and isolation, synthesis and decay, life and death. 
Therefore, it should be concluded that only living systems die, and not immediately, but starting from some point when the predominance of synthesis over decay (childhood and youth) and their equilibrium (maturity) is replaced by the dominance of decay over synthesis (aging). The beginning of aging means the activation of the process of delayed dying. Death is included from the very beginning in the process of life as a necessary condition for its renewal. But in the initial period of the existence of a living system, death is somewhere in the background, and then it declares itself and gradually takes over.

\section{From Theory to Practice}

Excluding death from the scope of consideration, modern life science does not model the life process in its entirety. This disadvantage has a negative impact on the field of practical medicine, but especially on the field of modern biomedicine. Practical medicine is currently engaged in the correction of the final stages of various destructive processes in the human body. The latest biomedicine focuses its efforts exclusively on rejuvenation, on the fight against aging, on achieving immortality. It uses the most up-to-date techniques: transplantology, stem cells, cloning, genetic engineering, genomic medicine (p. 242-247) [16]. And yet these methods are doomed to failure, because they have an impact only at the later stages of the life process, when the predominance of death over life has become irreversible. A new understanding comes: in order to prolong the existence of a living organism, it is necessary to influence the earlier stages of its existence (p. 262-265) [17].

But this requires conceptualizing death as a condition of life. Death must be interpreted as a factor that cannot be completely eliminated, but the effect of which can be postponed. This means that death should be introduced into the theory as a factor in the continuation of human life, then formulated as an objective condition for individual immortality. From a philosophical point of view, such a concept will become a theoretical formalization of the phenomenon of life involving the category of the universal. As a result, the former formulas, in which the ratio of the special and the individual (that is, the species and the individual) was expressed by the formulas immortal species - mortal individual and mortal species - mortal individual, will be replaced by a new formula immortal species immortal individual.

To develop a practical equivalent to this formula should not be on the path of ideological Luddism, that is, the rejection of the achievements of science, but, on the contrary, on the way of using the entire scientific potential to manage the life process on the scale of both the entire human species and a particular individual. In this case, medicine is naturally promoted to the role of the main social institution of modern society. However, this should not be the current medicine, but a new medicine with a fundamentally new clinical doctrine. This kind of doctrine needs to be developed in depth. As for it, at the moment, it is advisable to confine ourselves to considerations of the most general order.

The main drawback of the modern clinical doctrine is that it excludes the phenomenon of death. Therefore, modern medicine is limited to the correction of destructive manifestations in the late stages of the most common diseases today, namely cancer and cardiovascular pathology. In the new clinical doctrine, these diseases should be considered as special forms of the process of dying and at the same time the process of aging. Since the processes of dying and aging are evolutionary in nature, the new medicine should set the task of transforming all the factors of human existence as widely as possible. Such a transformation should be comprehensive. On the one hand, it will include the impact on the entire human race by optimizing the external environmental environment. On the other hand, it involves purposeful counteraction to the processes of dying in the individual human body through extremely early warning of the aging period. In this case, the death factor will become a consciously applied condition for prolonging the life of the human individual in a potentially infinite perspective.

\section{References}

[1] Chakrabarty Dipesh. Ob antropocene [About the Anthropocene]. Moscow: V-A-C Press, Artguide Editions, 2020. 160 p. (In Russ.).

[2] Gasparyan D. E., Styrin E. Pricladnie problem wnedrenja etiki iskusstvennogo intellect $v$ Rossii [M. Applied problems of implementing the ethics of artificial intelligence in Russia]. Moscow: Publishing House of the Higher School of Economics, 2020. 112 p. (In Russ.).

[3] Kutyrev V. A. Sova Minervi viletaet v polnoch [Minerva's Owl flies out into the twilight (Selected philosophical texts of the XXI century)]. St. Petersburg: Aleteia, 2018. 526 p. (In Russ.).

[4] Arthur Lovejoy. Velikaja cep bitija [The Great Chain of Being]. Moscow: Dom intellectualnoi knigi Publ., 2001. 376 p. (In Russ.).

[5] Alekseev V. P. Chelovek. Evolutia I taxonomia [Man. Evolution and taxonomy]. Alekseev V. P. Isbrannoe: $v 5 t$. T. 1. [Favorites: in 5 vol. Vol. 1]. Moscow: Nauka Publ., 2007. 687 p. (In Russ.)

[6] Biologia starenia. Rukovodstvo po fisiologii [Biology of aging. Manual of Physiology]. Leningrad: Nauka Publ., 1982. 616 p. (In Russ.).

[7] Dilman V. M. Chetyre modeli meditsyny \{Four models of medicine]. Moscow: Meditsina Publ., 1987. 288 p. (In Russ.).

[8] Lamb M. Biologia starenia [Biology of aging]. Moscow: Mir Publ., 1980. 208 p. (In Russ.).

[9] Filosofskij slovar. Pod red. I. T. Frolova. 6-e izdanie [Philosophical dictionary. Edited by I. T. Frolov. 6th edition]. Moscow: Politisdat Publ., 1991. 560 p. (In Russ.).

[10] Rybin V. A. Transhumanism kak problema ekologicheskogo crisisa [Transhumanism as a problem of ecological crisis] // Bulletin of the Chelyabinsk State University. Philosophical sciences. No. 13 (409). 2017. p. 12. (In Russ.). 
[11] Filosofskij enciklopedicheskij slovar. 2-e izdanie [Philosophical Encyclopedic Dictionary. 2nd edition]. Moscow: Sov. enciklopedia Publ., 1989. 815 p. (In Russ.).

[12] Spencer Herbert. Sinteticheskay filosofia [Herbert Spencer. Synthetic Philosophy]. Kiev: Nika Publ., 1997. 512 p. (In Russ.).

[13] Bergson Anri. Tvorcheskay evolutia [Creative evolution]. Moscow: Kanon Publ., 1998. 384 p. (In Russ.).

[14] Vernadskij V. I. Chimicheskoe stroenie biosferi Zemli i ee okrushenia [Chemical structure of the Earth's biosphere and its environment]. Moscow: Nauka Publ., 2007. 376 p. (In Russ.).
[15] Lewontin Richard C. Biology as Ideology. Concord, Ontario: Anansi Press Limited Publishing House, 1991. 100 p. (In Engl.).

[16] Skulachev V. P. Shisn bes starosti [Life without old age]. Moscow: Eksmo Publ., 2013. 256 p. (In Russ.).

[17] Polina Loseva. Protiv chasovoi strelki: Chto takoe; starenie I kak s nim borotsja [Counterclockwise: What is aging and how to deal with it]. Moscow: Alpina non-fiction Publ., 2020. 470 p. (In Russ.). 